\title{
A CURRENT CONCEPT OF THE REGULATION OF BLOOD VOLUME
}

\author{
BY
}

JAMES W. PEARCE

From the Department of Physiology and Pharmacology, University of Alberta, Edmonton, Alberta, Canada

Received June 26, 1960

To the unspecialized reader concerned with management of the ædema of disease, the rapid accumulation of proven influences on the renal regulation of extracellular electrolyte content and fluid volume may pose a problem in integration. This presentation does not constitute a comprehensive review (Smith, 1957; Grossman, 1957) but rather a summary of present understanding of a homeostatic mechanism, the existence of which is receiving tentative acceptance. This mechanism appears to operate primarily by correcting variations in the content of the intravascular compartment of extracellular fluid volume. Secondary changes in the same direction will normally occur almost concomitantly in the interstitial fluid compartment, which must be thought of as essentially continuous with the intravascular space. Exchange and distribution of fluid between these two compartments are chiefly determined by hydrostatic and colloid osmotic pressure differences and by capillary permeability. The latter factors may be grossly altered by disease but can play no active role in governing the overall volume of extracellular fluid in the normal state.

The work of Verney $(1947,1957)$ has already established the features of another mechanism evolved to maintain the constancy of osmotic pressure of body fluid. One may now visualize the sequence of events following water loading as a reduction in plasma osmotic pressure causing osmoreceptors in the anterior hypothalamus to reduce the secretion of antidiuretic hormone via the posterior pituitary gland, thus leading to a reduced renal tubular reabsorption of water and a consequent diuresis. This renal response corrects both the reduced osmotic pressure and the increased volume. The opposite situation, ingestion of a strongly hypertonic solution, leads to a retention of water by the kidney and to increased water intake which, although effective in returning osmotic pressure to normal, do so by enlarging extracellular fluid volume. This volume increase, like that produced by ingestion or infusion of isotonic solution and, on the other hand, the reduced volume following hæmorrhage are, in fact, followed by other appropriate renal responses that operate to restore normal volume. For some years the acceptance of a classical reflex mechanism to regulate blood volume has been delayed by refuge taken in the simpler view that increased blood volume must lead to increased renal blood flow and hence to greater renal output. An automatic regulating device is thus provided. The evidence is commonplace, however, that glomerular filtration rate does not necessarily vary with renal blood flow or with blood pressure. Even admitting the probability that tubular reabsorption may be influenced by renal hæmodynamic changes affecting the concentrating mechanism (Goodyear et al., 1958; Gottschalk and Mylle, 1959), the evidence that extrarenal factors are involved is now overwhelming. A logical approach to the understanding of a reflex mechanism for regulating blood volume would be a search for the classical components, a sensory limb to register volume, integrating and effector centres, and finally the effector systems operating to restore to normal the signals from the sensing device. 


\section{THE VOLUME RECEPTORS}

Receptors that could be expected to respond to changes in filling volume of the cardiovascular system might be located in the low pressure circulation or in the high pressure circulation. One of the early pieces of evidence pointing to a thoracic location of volume receptors was provided by Strauss et al. (1951), when they reported that ingestion of $2000 \mathrm{ml}$. of normal saline was followed by a prompt diuresis only if subjects were recumbent: subjects who remained upright retained the saline load over many hours. They concluded that the shift of blood volume toward the thorax, on lying down, stimulated receptors there that initiated the renal response. Later Gauer et al. (1954), during a study of negative pressure breathing in the dog, noted that a moderate diuresis usually accompanied this procedure, one that is known to shift blood from the peripheral vasculature into the thoracic viscera. Reasoning that the responsible thoracic receptors should be found in the most distensible portion of the cardiovascular system, the low-pressure side, Henry et al. (1956) performed experiments in which distension of a balloon in the left atrium led to a prompt and largediuresis. This renal response could not be evoked by pulmonary vascular engorgement achieved by constriction of the pulmonary veins, a manœuvre that could be expected to produce similar effects on the greater circulation. The diuretic responses to both negative pressure breathing and left atrial distension were usually prevented or much reduced by cold block of the vagus nerves. Henry and Pearce (1956) then showed that left atrial stretch receptors, the vagal activity of which was clearly described in the cat by Paintal (1953), did respond in the dog with strikingly increased activity during atrial balloon distension but with only a modest increase in discharge during negative pressure breathing. The evoked diureses consisted of increases in water output without significant alteration in electrolyte excretion, a feature also of the diuretic response to similar negative pressure breathing in the human subject (Sieker et al., 1954). Atrial stretch receptors, which have also been found in the monkey (Chapman and Pearce, 1959), an upright primate like man, do then seem to provide at least one set of "volume receptors" responsible for reflex changes in urine volume seen to follow blood volume expansion.

If atrial receptors constituted the only volume receptors, section of the vagus nerves should prevent the renal response to physiological expansion of the blood volume resulting from infusion into the circulation of isotonic plasma substitutes and of whole blood (Zuidema et al., 1956). Such was not the case in the experiments of Atkins and Pearce (1959) and Pearce (1959), in which vagotomy usually reduced, but failed to prevent, the diuretic responses in dogs to infusions of bovine albumin solution in saline or of plasma. These renal responses, like those described earlier in human subjects by Welt and Orloff (1951), included a natriuretic component, not seen when the volume expansion was limited to the thoracic viscera. Hence receptors in addition to those in the cardiac chambers had to be involved. Other regions of the low pressure circulatory system seemed unlikely sites for these additional receptors, as engorgment of the limb veins with tourniquets (Judson et al., 1952), cephalic veins (Fishman, 1953) and abdominal veins (Davis, et al., 1956) has in each case been shown to reduce urine flow or electrolyte excretion or both. Epstein (1956) has proposed that receptors in the high pressure circulation must contribute to the regulation of blood volume. Although combined denervation of the carotid sinuses and vagotomy failed to prevent the diuretic and natriuretic response to infusion of bovine albumin solution (Pearce, 1959), Bartter and Gann (1959) have recently reported experiments that clearly implicated a third buffer nerve (Gann and Bartter, 1959), the common carotid, in the regulation of urinary sodium output. This nerve, described first by Green (1953), arises in an arterial baroreceptor zone near the origin of the thyroid artery from the common carotid, and as it joins the nodose ganglion of the vagus it could escape the combined denervation procedures described above. Bartter's experiments show that reduced stimulation of the common carotid baroreceptors, which could result either from a fall in mean arterial pressure or in pulse pressure, leads to an increase in secretion of aldosterone and a consequent decrease in urinary sodium output. Although changes in mean arterial pressure associated with alterations in cardiac output following physiological changes in blood volume are not large or sustained (because 
of the regulation of vasomotor activity which is the primary function of the baroreceptors), variations in pulse pressure do persist. The implications of Bartter's findings in the regulation of aldosterone secretion in congestive heart failure, where the cardiac output is usually reduced and hence also the pulse pressure, will be referred to later.

Bartter and his colleagues (Mills et al., 1958) also showed that the rise in secretion of aldosterone that followed constriction of the inferior vena cava, a manœuvre that would not only reduce cardiac output but also deprive the thoracic viscera of normal filling volume, did not depend on the integrity of the vagus nerves. The return to normal of the aldosterone level following release of the constriction did, however, depend on the presence of intact vagus nerves. Although it is difficult at this time to assess the effect of the tachycardia of vagotomy on the arterial pulse pressure, these observations, associated with those of Anderson et al. (1959) that mechanical stretching of the right atrium resulted in a lowered aldosterone secretion, suggest the following concept. The receptors of the high pressure system appear to initiate the liberation of increased quantities of aldosterone in response to a decreased pulse pressure, a reflection primarily of stroke cardiac output. On the other hand, the receptors of the low pressure system, while not concerned in the stimulation of increased aldosterone output, appear to participate at least in the return to normal of a raised rate of secretion when normal thoracic blood content is restored, or to reduce the rate of secretion below normal if thoracic blood volume is excessive. Such an interpretation would be consistent also with the finding that vagotomy alone does not lead to an increase in aldosterone output (Davis et al., 1959). This concept must be held as tentative, however, as the evidence for such an unorthodox "on-off" mechanism is still far from complete and cold block of the vagi has also been shown to reduce aldosterone secretion below normal (Anderson et al., 1958). It must also be noted that vagotomy fails to produce oliguria in unhydrated animals (Pearce, 1959). In such animals antidiuretic hormone levels may already be nearly maximal, and the studies should be repeated in animals undergoing diuresis following hypotonic infusions.

Assuming that volume regulating receptors exist in both the low and high pressure sides of the cardiovascular system, need the search be extended for receptors of interstitial fluid volume? Although it is difficult experimentally to change the interstitial fluid volume without simultaneously altering the circulating blood volume, changes in opposing directions may be achieved by grossly altering the oncotic pressure of the plasma. Welt and Orloff (1951) and later Fine et al. (1958) have shown that increase in intravascular volume at the expense of interstitial fluid volume, produced by infusion of hyperoncotic albumin solution, will lower urinary sodium output or fail to correct a raised aldosterone level previously produced by hæmorrhage. Hence, in spite of increased blood volume, reduction of interstitial fluid volume, presumably without change in sodium concentration, can result in compensating urinary sodium retention. There are now indications that the midbrain plays a controlling role in regulating aldosterone output and it is not inconceivable that receptors exist there that are designed to register changes in the degree of separation of cells. However, it would be extremely interesting to know how expansion of the interstitial fluid space would affect discharge of baroreceptors by alteration in the fluid content of their supporting cells.

\section{EFFECTOR MECHANISMS}

Changes in circulating blood volume that lead to changes in vascular pressures must, by the classical Starling-Landis mechanism, be reflected in alterations in the same direction in capillary ultrafiltration. The fluid movement can amount to appreciable quantities, as evidenced by the hæmodilution that follows moderate hæmorrhage and the concentration of plasma protein that follows infusion of autologous plasma (Remington and Baker, 1959). Coupled with this passive mechanism is the reflex adjustment of vascular capacity that follows detection of arterial pressure fluctuations by the baroreceptors (Heymans and Neil, 1958) and possibly also detection of altered filling volume by atrial stretch receptors (Roddie and Shepherd, 1958). These two responses provide immediate buffering of abrupt changes in blood volume. 
A secondary line of defence, provided by the kidney, consists of alteration of water and electrolyte output. It is now clear that variation in the rate of secretion of antidiuretic hormone at least contributes to the increased water excretion seen following the infusion of isotonic bovine albumin solution (Orloff and Blake, 1951), during negative pressure breathing (Boylan and Antkowiak, 1959), and atrial balloon distension in dogs (Baïsset et al., 1958) and to the decreased water excretion following orthostasis (Pearce and Newman, 1954) and hæmorrhage (Rydin and Verney, 1938). Although it is a common finding that the glomerular filtration rate does not rise in response to increase in extracellular fluid volume (thus relegating the renal response to a tubular mechanism), moderate hæmorrhage is usually associated with reduction in glomerular filtration, which can explain part of the reduced renal output of water.

It has been clearly shown that urinary sodium output decreases following hæmorrhage(Goodkind et al., 1957), reduction of extracellular fluid volume without change in serum sodium concentration (Bartter et al., 1956), and orthostasis (Epstein et al., 1951; Thomas, 1957; Pearce and Newman, 1954). The workers cited found, however, that the glomerular filtration rate did not change or increased or that decreased filtration, when observed, did not account for the reduction in sodium output. Increased urinary sodium excretion has bəen demonstrated following infusions of bovine albumin in man (Welt and Orloff, 1951) and of either bovine albumin solution or plasma in the dog (Atkins and Pearce, 1959) and following expansion of the extracellular fluid volume in man (Bartter et al., 1956), even with a lowered plasma sodium concentration (Weston et al., 1953). Again, these changes in sodium output could only be completely accounted for by decreased tubular reabsorption.

Since methods of assay of aldosterone levels in the urine became available (Simpson and Tait, 1952; Singer and Venning, 1953), attention has been focused on the level of this steroid as the important extrarenal factor governing urinary sodium output. The evidence has accumulated that hæmorrhage does indeed increase aldosterone output (Farrell et al., 1956; Bartter et al., 1958) as do reduction in extracellular fluid volume (Bartter et al., 1956), orthostasis (Gowenlock et al., 1958), and reduction in thoracic blood volume produced by constriction of the inferior vena cava (Mills et al., 1958). The early evidence that aldosterone output is decreased by increased central blood volume was based on somewhat unnatural alterations in the circulatory systems of dogs, but the recent studies of Bartter et al. (1958), using infusions of albumin solution in man, have established this point. Gowenlock et al. (1958) have also reported a fall in urinary aldosterone output to follow recumb zncy in man.

Exception must be taken, however, to the acceptance of an exclusive role of aldosterone in governing the renal output of sodium in normal blood volume regulation. Variations in urinary sodium output produced by orthostasis or other manœuvres designed to shift the circulating blood volume, and shown to be the result of altered tubular reabsorption, have been observed in patients with Addison's disease (Rosenbaum et al., 1955; Taymor and Friedberg, 1957). Natriuresis following plasma infusion has been reported in adrenalectomized dogs (Atkins and Pearce, 1959). Most studies of natural aldosterone levels are carried out over a period of days, and infusion of the steroid produces a slow and modest effect which may outlast by several hours the actual period of administration (Ross et al., 1959; Barger et al., 1958). It seems difficult, then, to attribute the abrupt and large changes in sodium excretion following a number of experimental variations in blood volume to the liberation or disappearance of the hormone in the blood stream. While not denying a role of aldosterone in blood volume regulation, it seems wise to speculate as well on other possible effector mechanisms provided to alter urinary sodium output.

The existence of a "natriuretic hormone" is not a new suggestion, but one strongly supported by recent work by Keeler (1959). Lesions placed in the lateral hypothalamus of the rat resulted in a threefold increase in urinary sodium excretion, which was not prevented by renal denervation, hypophysectomy, or adrenalectomy. These lesions also reversed the usual decrease in sodium output that followed reduction of the extracellular fluid volume by peritoneal dialysis with 25 per cent acacia solution. A "sodium-losing material" has also been reported in the urine of patients with congenital adrenal hyperplasia (Klein et al., 1958), and this might explain the apparent refractoriness to continuous aldosterone administration to human subjects in whom sodium and water retention 
ceases when a critical weight gain has resulted (August et al., 1958). A second alternative natriuretic mechanism that has been proposed is a direct nervous control of tubular reabsorption, but there appears to be no evidence of this that cannot also be explained on the basis of humoral factors now being revealed. A third and more likely mechanism depends on intrarenal hæmodynamic changes, the effect of which must be considered in the light of recent revisions in understanding of the renal tubular concentrating process. As the efficacy of the concentrating gradient established in the renal medulla by the proposed countercurrent mechanism must depend in part on the rate of blood flow through the medullary vessels (Gottschalk and Mylle, 1959), both urine volume and solute content could be influenced either by the distribution of renal blood flow or by the absolute flow rate. Goodyer et al. (1958) have also provided some evidence of a related mechanism operating in response to hæmorrhage, the intrarenal shunting of blood to "vessels of less than average resistance perfusing nephrons of more than average sodium reabsorbing capacity". Such changes could still be dictated by extrarenal influences, including the innervation of kidney vasculature (Sartorius and Burlington, 1956; Bálint and Fekete, 1958) or by circulating hormones to which kidney vessels are differentially sensitive. The possibility also exists that redistribution of intrarenal blood flow depends on the viscosity of the blood, although this is unlikely to explain renal responses to simple translocation of circulating blood volume.

\section{ReFlex CENTRES}

Although the detailed pathways of visceral afferent nerves remain to be revealed, there is some histological evidence that the sensory vagal nucleus (receiving impulses from cardiovascular receptors) has connections via the dorsal longitudinal bundle with the hypothalamic and posterior midbrain nuclei (Crosby and Woodburne, 1951). Vagal afferents, probably from atrial stretch receptors, can vary the secretion of antidiuretic hormone by the cells of the anterior hypothalmic nuclei. Approximately the same region must include the pathways or centres for the natriuretic mechanism studied by Keeler. The work of Farrell and his associates now implicates the posterior midbrain structures in the ultimate regulation of adrenal steroid secretion (Newman et al., 1958). Lesions placed centrally in the upper hindbrain increased the levels of plasma aldosterone in experimental animals, whereas lesions placed in the midbrain led to a decrease in aldosterone secretion. Attention was then directed to the pineal gland as a possible source of a hormone, released in response to stimulation from hypothalmic centres, which in turn governed adrenal cortical output of aldosterone. Pinealectomy was found to decrease blood levels of aldosterone in dogs (Farrell et al., 1959) and extracts of the pineal tissue were found to possess, in the acetone-soluble fraction, a powerful stimulating effect on aldosterone production (Farrell, 1959). The active material has been called "glomerulotropin" as it acts on the zona glomerulosa of the adrenal gland. More recent studies by Farrell (1960) indicate that the pineal gland may only act as a storehouse for a principle elaborated by other structures, possibly the subcommissural organ which was implicated by Gilbert (1957) as a "regulator of water intake" in the rat. Although the evidence is fresh, it seems likely that the pineal gland plays a role similar to that of the pituitary gland, and that integrating centres for the regulation of urinary sodium output exist in the posterior midbrain. Again, it is not difficult to postulate appropriate connections with baroreceptor nerve endings in the medulla, only a few interneurones away, so to speak.

The mode of integration of the diencephalic centres poses a formidable investigational problem: the light shed in solving this problem would aid in an understanding of the disordered salt and water metabolism of disease. Most homeostatic mechanisms operate continuously to maintain the level of a function constant; if the afferent pathway of the mechanism is suddenly interrupted there is usually a violent positive operation of the function. Yet separate and combined vagotomy and section of carotid sinus nerves in the dog have no acute effects on renal secretion of water and sodium chloride (Atkins and Pearce, 1959) and no lasting effects on aldosterone and urinary sodium excretion (Davis et al., 1959). Since the physiological causes of reduced activity in the vagus and the arterial baroreceptor nerves are not normally opposing ones, the results of combined section should not 
cancel one another out. It is also unlikely that the remaining impulses in the common carotid nerves, which would be increased in number because of the resultant hypertension, could dictate complete stability of water and salt output. The only ready answer is that still other receptors had been left intact and that they continued to register a normal state of extracellular fluid volume.

\section{An Attempt at Integration and Relation to CEdema of Cardiac Disease}

The mechanisms of extracellular fluid volume regulation for which there is now evidence are presented in Fig. 1 and 2. It is apparent that slightly different mechanisms operate to correct an

REGUL.ATION OF EXTRACELLULAR FLUID VOLUME (ECFV).

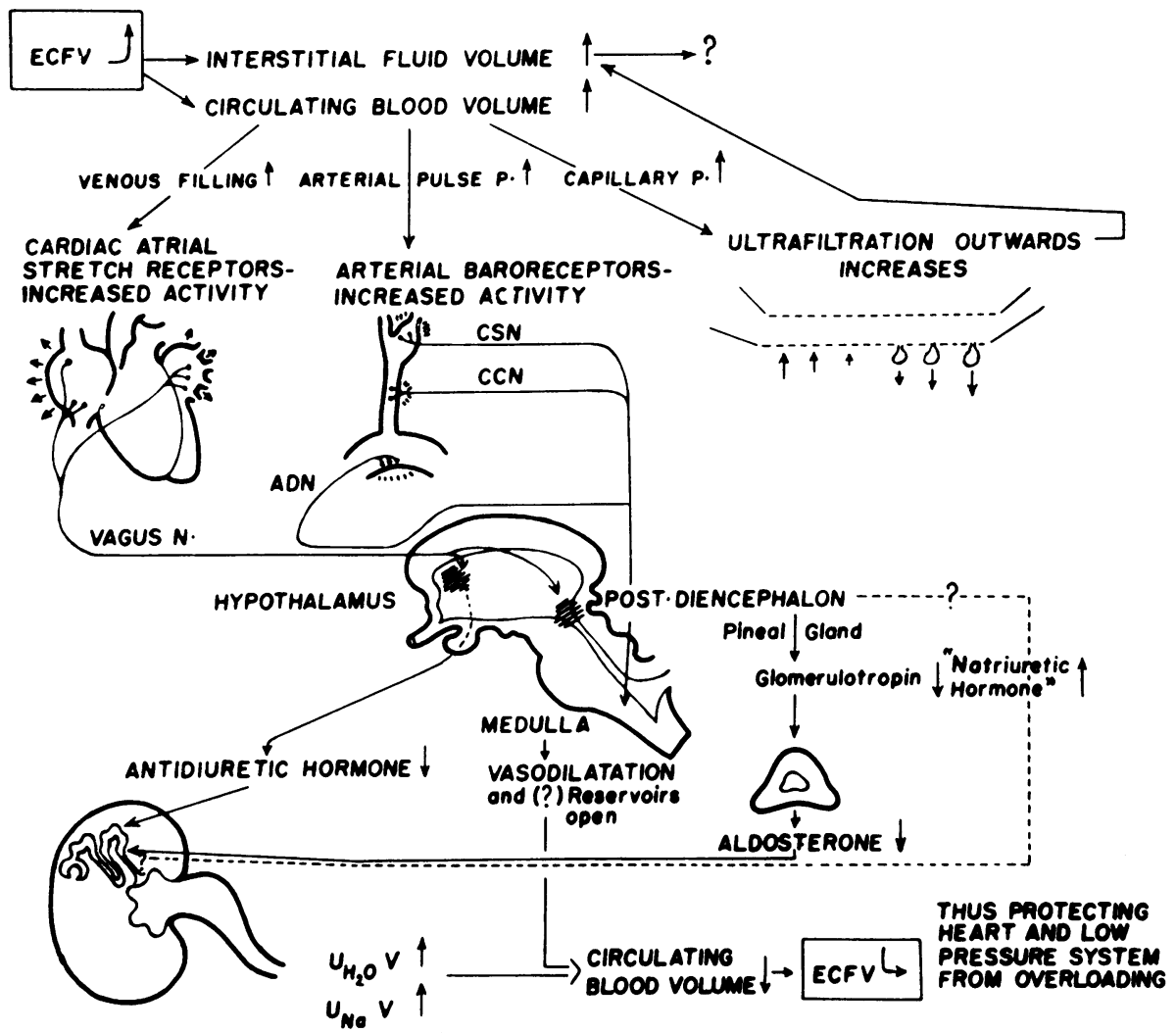

FIG. 1.-A diagram of proposed mechanisms by which an increase in extracellular fluid volume (ECFV) is counteracted. Those features for which evidence is still only preliminary are indicated by small lettering or by interrupted pathways. ADN, aortic depressor nerves; $\mathrm{CSN}$, carotid sinus nerves; $\mathrm{CCN}$, common carotid nerves; $\mathrm{UH}_{2} \mathrm{OV}$ and $\mathrm{UNaV}$, total urinary water and sodium excretion.

increase from those that correct a decrease in blood volume. It is suggested that one set of responses to increased blood volume exists to protect the heart and low pressure vascular system from overloading, while the other set of responses to decreased blood volume exists to ensure an adequate arterial supply and consequent tissue fluid circulation. The reduced cardiac output of the "forwardfailing" heart, detected first as a reduced pulse pressure in the arterial system, would lead to increased aldosterone secretion and consequent salt retention. A subsequent over-stimulation of the atrial receptors, due to venous congestion of "backward-failure", should lead to an increased output of urinary water. The inhibiting effect on antidiuretic hormone secretion is, however, not a powerful 


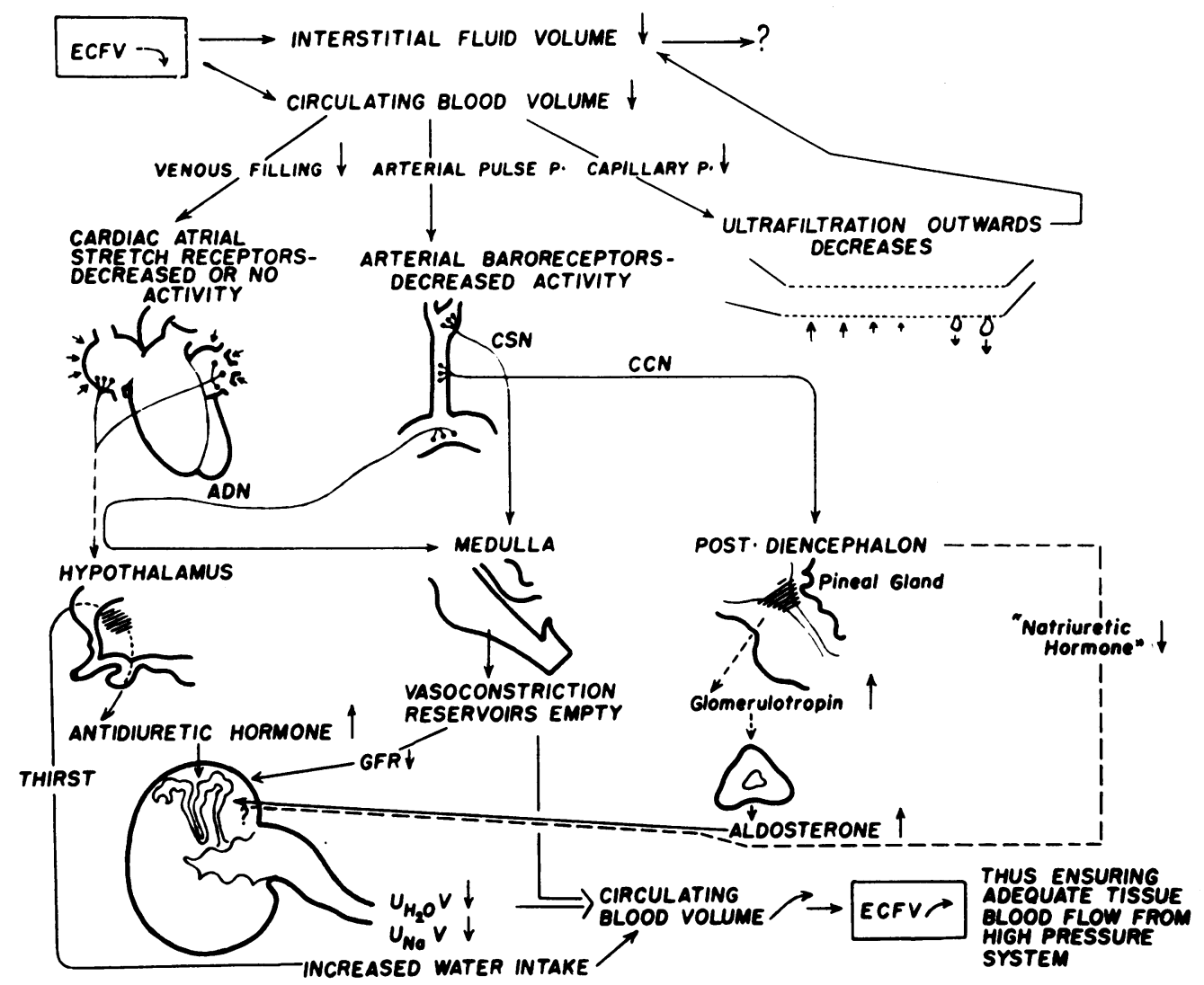

Fig. 2.-A diagram of proposed mechanisms by which a decrease in extracellular fluid volume (ECFV) is counteracted. Reservations and abbreviations are as in Fig. 1.

one (as seen with the modest atrial engorgement which accompanies negative pressure breathing) and it might be unable to oppose the stronger stimulus to antidiuretic hormone secretion arising from retention of osmotically active sodium. Although the atrial receptors do appear to influence electrolyte output during conditions leading to their prolonged overstimulation, again the powerful effect of reduced baroreceptor activity might predominate in increasing aldosterone secretion. So only a "natriuretic hormone", perhaps liberated in response to gross increase in interstitial fluid volume, would seem left to prevent unlimited and self-aggravating cardiac odema.

Initial backward failure should lead to diuresis, due to stimulation of atrial receptors, with perhaps some reduction in aldosterone secretion if the stimulus is large enough to imitate the stretching manœuvre of Farrell. Again, a persisting loss of water without proportionate loss of sodium defeats the mechanism by raising the extracellular fluid osmotic pressure. It seems that the moment the cardiac output began to decline, the low pressure side would be powerless to prevent salt and water retention. In experimental congestive failure, produced in dogs by circulatory obstruction (Davis et al., 1956), constriction of the inferior vena cava was much more effective in raising aldosterone secretion than constriction of the pulmonary artery. Assuming that the degree of reduction in cardiac output was similar in each case, it can be concluded that the engorgement of the right atrium at least mitigated the salt retention. Unfortunately, this is not borne out in the study of Wolff et al. (1957) who found a greater rise of aldosterone levels in the urine of patients with 
right-sided failure than in those with left-sided failure. Other workers have not been able to find raised aldosterone levels in experimental congestive failure, even in the presence of odema with salt and water retention (Driscoll et al., 1957). The high levels of aldosterone seen with hepatic cirrhosis may be due to interference with the inactivation of the steroid by the liver, although this does not seem to be the explanation of the high aldosterone levels of acute inferior vena cava constriction as they can be restored to normal by simultaneous infusion of blood into the supradiaphragmatic vasculature (Bartter and Gann, 1960). It seems that a profitable approach to the problem would be further careful study of the cardiac output and arterial pulse pressure in relation to aldosterone levels during various stages of cardiac decompensation and recompensation.

Other interesting hypotheses have been advanced to explain the œdema of congestive failure. Barger's suggestion that increased renal tubular reabsorption may be explained by an excessively high peritubular capillary oncotic pressure has received support from a recent study by Vander $e t$ al. (1958). Marked elevation of filtration fraction, due chiefly to fall in effective renal plasma flow, was found commonly in patients with œdema of congestive failure. This mechanism requires further examination in the light of newer concepts of the renal concentrating mechanism. Barger et al. (1959) have recently supplemented the original hypothesis by proposing that decreased baroreceptor activity of forward failure may be responsible for the reduced renal plasma flow. Most recently, Nelson and August (1959) have suggested that an abnormal response to aldosterone may exist in patients with œdema (of various types), as they do not show the normal refractoriness to continued administration of excessive aldosterone. A relation between these findings and altered pineal secretion, or possibly changed secretion of "natriuretic hormone", would be a revelation of great interest.

\section{SUMmaRY}

In addition to mechanisms for the regulation of osmotic pressure of the extracellular fluid, the major factor determining intracellular volume (Robinson, 1960), a complex mechanism exists for the regulation of extracellular fluid volume. The latter mechanism appears to depend upon sensory information from volume receptors in the low pressure and high pressure sides of the circulation, and possibly also in the interstitial fluid compartment. The volume of the extracellular compartment is adjusted first by changes in circulating blood volume, brought about by alterations in urinary water and electrolyte output. The low pressure system receptors appear to regulate mainly the renal water output by varying the level of secreted antidiuretic hormone: their function may be conceived as the protection of the low pressure system and heart from overloading. The high pressure system receptors appear to regulate mainly the sodium output by varying the production of aldosterone; the parameter of pulse pressure, related to stroke cardiac output, is probably the relevant stimulus to volume regulation by these receptors, the function of which may be conceived as the maintenance of adequate tissue fluid circulation. An additional regulation of urinary sodium excretion must exist, and there is evidence supporting at least two possible mechanisms: a natriuretic hormone, secreted in the midbrain, or renal hæmodynamic control of the tubular concentrating mechanism. The coordinating centres for the homeostasis of blood volume seem to lie in the midbrain, with the anterior hypothalamic centres controlling water output and the posterior diencephalic centres, possibly including the pineal gland, controlling sodium output.

The salt retention of cardiac failure can, in some cases only, be explained on the basis of reduced cardiac output leading to increased aldosterone secretion in spite of the overruled opposing influence from engorgement of the lesser circulation. An abnormally increased renal reabsorption of water and salt, due to a raised filtration fraction or an enhanced sensitivity to aldosterone, may contribute to salt and water retention in œdema. Although its disorder in disease is poorly understood, the existence of a mechanism to regulate blood volume in the normal state must now be accepted among the homeostatic mechanisms designed "to maintain the constancy of the internal environment".

\section{REFERENCES}

Anderson, C. H., McCally, M. , and Farrell, G. L. (1958). Circulation, 18, 688. (1959). Endocrinology, 64. 202. 
Atkins, E. L., and Pearce, J. W. (1959). Canad. J. Biochem. Physiol., 37, 91.

August, J. T., Nelson, D. H., and Thorn, G. W. (1958). J. clin. Invest., 37, 1549.

Baîsset, A., Douste-Blazy, L., Montastruc, P., and Valdiguié, P. (1958). C. R. Soc. Biol., Paris, $13,378$.

Bálint, P., and Fekete, A. (1958). Pflüg. Arch ges. Physiol., 268, 168.

Barger, A. C., Berlin, R. D., and Tulenko, J. F. (1958). Endocrinology, 62, 804. Muldowney, F. P., and Liebowitz, M. R. (1959). Circulation, 20, 273.

Bartter, F. C., Liddle, G. W., Duncan, L. E., Barber, J. K., and Delea, C. (1956). J. clin. Invest., 35, 1306. Biglieri, E. G., Pronove, P., and Delea, C. S. (1958). An International Symposium on Aldosterone. Churchill, London. and Gann, D. S. (1960). Circulation, 21, 1016.

Boylan, J. W., and Antkowiak, D. E. (1959). J. appl. Physiol., 14, 116.

Chapman, K. M., and Pearce, J. W. (1959). Nature, 184, 1237.

Crosby, E. C., and Woodburne, R. T. (1951). J. comp. Neurol., 94, 1.

Davis, J. O., Goodkind, M. J., Pechet, M. M., and Ball, W. C. (1956). Amer. J. Physiol., $187,45$. Yankopoulos, N. A., and Holman, J. (1959). Amer. J. Physiol., 197, 207.

Driscoll, T. E., Maultsby, M. M., Farrell, G. L., and Berne, R. M. (1957). Amer. J. Physiol., $191,140$.

Epstein, F. H., Goodyer, A. V. N., Lawrason, F. D., and Relman, A. S. (1951). J. clin. Invest., $30,63$. (1956). Yale. J. biol. Med., 29, 282.

Farrell, G. L., Rosnagle, R. S., and Rauschkolb, E. W. (1956) Circulation Res., 4, 606. Koletsky, S., and Lapham, L. W. (1959). Fed. Proc., 18, 44.

(1959). Endocrinology, 65, 239.

(1960). Circulation, 21, 1009.

Fine, D., Meiselas, L. E., and Auerbach, T. (1958). J. clin. Invest., 37, 232.

Fishman, R. A. (1953). J. clin. Invest., 32, 847.

Gann, D. S., and Bartter, F. C. (1959). Amer. J. Physiol., 197, 1229.

Gauer, O. H., Henry, J. P., Sieker, H. O., and Wendt, W. E. (1954). J. clin. Invest., 33, 287.

Gilbert, G. J. (1957). Amer. J. Physiol., 191, 243.

Goodkind, M. J., Ball, W. C., and Davis, J. O. (1957). Amer. J. Physiol., 189, 181.

Goodyer, A. V. N., Mattie, L. R., and Chetrick, A. (1958). Amer. J. Physiol., 193, 360.

Gottschalk, C. W., and Mylle, M. (1959). Amer. J. Physiol., 196, 927.

Gowenlock, A. H., Mills, J. N., and Thomas, S. (1958). J. Physiol., 143, 9P.

Green, J. H. (1953). J. Physiol., 122, 70P.

Grossman, J. (1957). Arch. intern. Med., 99, 93.

Henry, J. P., Gauer, O. H. and Reeves, J. L. (1956). Circulation Res., 4, 85.

-, and Pearce, J. W. (1956). J. Physiol., 131, 572.

Heymans, C., and Neil, E. (1958). Reflexogenic Areas of the Cardiovascular System, Churchill, London.

Judson, W. E., Hatcher, J. D., Halperin, M. H., and Wilkins, R. W. (1952). J. clin. Invest., $31,642$.

Keeler, R. (1959). Amer. J. Physiol., 197, 847.

Klein, R., Taylor, P., Papadatos, C., Laron, Z., Keel, D., Fortunado, J., Byers, C., and Billings C. (1958). Proc. Soc. exp. Biol., N.Y., 98, 863.

Mills, I. H., Casper, A. and Bartter, F. C. (1958). Science, 128, 1140.

Nelson, D. H., and August, J. T. (1959). Lancet, 2, 883

Newman, A. E., Redgate, E. S., and Farrell, G. (1958). Endocrinology, 63, 723.

Orloff, J., and Blake, W. D. (1951). Amer. J. Physiol., 164, 167.

Paintal, A. S. (1953). J. Physiol., 120, 596.

Pearce, J. W. (1959). Canad. J. Biochem, Physiol., 37, 91.

Pearce, M. L., and Newman, E. V. (1954). J. clin. Invest., 33, 1089.

Remington, J. W., and Baker, C. H. (1959). Amer. J. Physiol., 197, 193.

Robinson, J. R. (1960). Physiol. Rev., 40, 112.

Roddie, I. C., and Shepherd, J. T. (1958). Lancet, 274, 493.

Rosenbaum, J. D., Papper, S., and Ashley, M. M. (1955). J. clin. Endocr. Metab., 15, 1459.

Ross, E. J., Reddy, W. J., Rivera, A., and Thorn, G. W. (1959). J. clin. Endocr. Metab., 19, 289.

Rydin, H., and Verney, E. B. (1938). Quart. J. exp. Physiol., 27, 343.

Sartorius, O. W., and Burlington, H. (1956). Amer. J. Physiol., 185, 407.

Sieker, H. O., Gauer, O. H., and Henry, J. P. (1954). J. clin. Invest., 33, 572.

Simpson, S. A., and Tait, J. F. (1952). Endocrinology, 50, 150.

Singer, B., and Venning, E. H., (1953). Endocrinology, 52, 623.

Smith, H. W. (1957). Amer. J. Med., 23, 623.

Strauss, M. B., Davis, R. K., Rosenbaum, J. D., and Rossmeisl, E. C. (1951). J. clin. Invest., $30,862$.

Taymor, R. C., and Friedberg, C. K. (1957). J. appl. Physiol., 11, 125.

Thomas, S. (1957). J. Physiol., 139, 337.

Vander, A. J., Malvin, R. L., Wilde, W. S. and Sullivan, L. P. (1958). Amer. J. Med., $25,497$.

Verney, E. B. (1947). Proc. Roy. Soc. B., 135, 25. (1957). Lancet, 273, 1237.

Welt, L. G., and Orloff, J. (1951). J. clin. Invest., 30, 751.

Weston, R. E., Hanenson, I. B., Grossman, J., Berdasco, G. A., and Wolfman, M. (1953). J. clin. Invest., $32,611$.

Wolff, H. P., Koczorek, K. R., and Buchborn, E. (1957). Lancet, 273, 63.

Zuidema, G. D., Clarke, N. P., Reeves, J. L., Gauer, O. H., and Henry, J. P. (1956). Amer. J. Physiol., $186,89$. 